\title{
Correlation Between Clinical and Histopathologic Diagnosis of Oral Potentially Malignant Disorder and Oral Squamous Cell Carcinoma
}

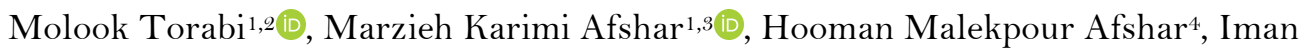 \\ Mohammahzadeh ${ }^{5}(0)$
}

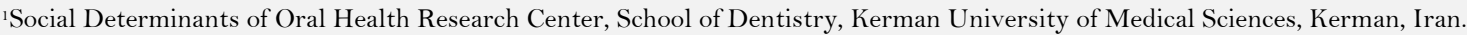
¿Department of Maxillofacial Pathology, School of Dentistry, Kerman University of Medical Sciences, Kerman, Iran.

${ }^{3}$ Department of Orthodontics, School of Dentistry, Kerman University of Medical Sciences, Kerman, Iran.

${ }^{4}$ School of Dentistry, Kerman University of Medical Sciences, Kerman, Iran.

${ }^{5}$ Oral and Dental Diseases Research Center, Kerman University of Medical Science, Kerman, Iran.
\end{abstract}

Correspondence: Marzieh Karimi Afshar, Orthodontics Department, School of Dentistry, Kerman University of Medical Sciences, Shafa Ave, Jomhoori Islami BLVD, Kerman 7618759689, Iran. E-mail: marzieh.k.afshar@gmail.com

Academic Editor: Alidianne Fábia Cabral Cavalcanti

Received: 21 June 2020 / Review: 25 November 2020 / Accepted: 09 December 2020

How to cite: Torabi M, Afshar MK, Afshar HM, Mohammahzadeh I. Correlation between clinical and histopathologic diagnosis of oral potentially malignant disorder and oral squamous cell carcinoma. Pesqui Bras Odontopediatria Clín Integr. 202 1; $21: \mathrm{e} 0143$. https://doi.org/10.1590/pboci.2021.068

\begin{abstract}
Objective: To determine the frequency of oral potentially malignant disorders and Oral Squamous Cell Carcinoma (OSCC) and evaluate the consistency between their clinical and pathological features. Material and Methods: This retrospective study was conducted on records with a diagnosis of oral leukoplakia, oral erythroplakia, erythroleukoplakia, actinic cheilitis, lichen planus, and OSCC in the Pathology Department of Kerman dental school from September 1997 to September 2017. Data were analyzed in SPSS 21 at the significance level of $\leq 5 \%$. Results: There were 378 cases of oral potentially malignant disorders and 70 cases of OSCC with a mean age of $46.82 \pm 15.24$ years. Buccal mucosa was the most frequent site, and lichen planus the most common lesion. Females were significantly older than males in leukoplakia and carcinoma in situ lesions. Clinical diagnosis and histopathology were consistent in $69.03 \%$ of cases. Conclusion: Clinical and histopathological diagnoses were consistent in $69.03 \%$ of records. The highest degree of clinical compliance with histopathology was observed in OSCC. Dentists should pay attention to oral potentially malignant disorders for early diagnosis to prevent their transformation to malignancy.
\end{abstract}

Keywords: Pathology, Oral; Mouth Neoplasms; Carcinoma, Squamous Cell; Leukoplakia, Oral. 


\section{Introduction}

Oral cancer is the sixth most common cancer with varying prevalence around the world [1]. Oral squamous cell carcinoma (OSCC) is the most common cancer of the oral cavity and accounts for $95 \%$ of all oral cavity cancer instances [2]. OSCC is diagnosed based on clinical examinations and histological findings of oral biopsy [1]. The 5-year survival rate of OSCC has remained around 50\% over the last three decades [3].

Early diagnosis and treatment of malignancy usually improve long-term treatment and survival rate [4]. Previous conditions conducive to cancer are referred to as premalignant lesions. These lesions are morphologically altered tissues observed in clinical examinations that are more likely than normal tissues to develop into cancer $[5,6]$. These lesions may be precancerous or premalignant and show epithelial dysplasia in histopathologic examinations [6].

The World Health Organization prefers the term “Oral Potentially Malignant Disorders” (OPMD) for lesions that are clinically prone to develop into oral cancer [7,8], such as leukoplakia, erythroplakia, lichen planus, hyperkeratosis [5], and submucous fibrosis [9]. This term has been introduced because studies have shown that all precancerous lesions do not progress to malignancy, and some are reversible by discontinuation of a habit [5].

According to Bokor-Bratiæ et al. [10], the most common OPMD in clinical diagnoses is leukoplakia (58.9\%). Clinical diagnosis was confirmed by histopathologic diagnosis in 92.3\% of leukoplakia patches [10]. Maia et al. [11] found that 31.2\% had OPMD. Regarding the relationship between clinical and histopathologic diagnoses, the highest consistency was observed in erythroplakia and atypical ulcers. A variety of diagnoses from hyperkeratosis to severe dysplasia was seen between six pathologists. Fitty point five (50.5) percent of pathologists accurately diagnosed mild-to-moderate dysplasia [12].

In addition to clinical features, microscopic and radiographic views of the lesions are necessary for a definitive diagnosis [13]. Early diagnosis of OPMD has a great clinical significance in preventing disease development and achieving more successful treatments. As a result, it increases the life expectancy and quality of life for patients.

Therefore, in continuing our interest in the medical research [14-16] and given the varied prevalence and type of premalignant and malignant lesions in different societies and the fact that clinical features cannot provide definitive diagnoses for several lesions, the consistency of clinical and histopathologic diagnoses gains significance for definitive, precise, and, particularly, early diagnoses of premalignant lesions as the main goal of treatment. Accordingly, the present study aimed to evaluate the consistency between the clinical and histopathological features of oral potentially malignant disorders and oral squamous cell carcinoma in a 20year period.

\section{Material and Methods}

Study Design

This was a retrospective descriptive-analytical whose population included the medical records of the maxillofacial Pathology Department of Kerman University of Medical Sciences School of Dentistry from September 1997 to September 2017

\section{Data Collection}

In this regard, a trained senior student and an expert oral pathologist reviewed the department archive. All premalignant lesions (lichen planus, leukoplakia, erythroplakia, hyperkeratosis, actinic cheilitis) 
and OSCC were identified and microscopic diagnosis was confirmed. Records with descriptive histopathologic diagnoses, i.e., without definitive microscopic diagnosis despite clinical diagnosis of leukoplakia and erythroplakia, were reevaluated and excluded if definitive histopathologic diagnoses were not possible.

Data recorded in a checklist that included information about clinical characteristics including location, clinical diagnosis, histopathologic diagnosis, and patients' demographic characteristics including name, age, gender.

Data Analysis

Data were analyzed by Cohen's kappa and T-test. The significance level was considered 0.05.

\section{Ethical Clearance}

This research proposal was approved by Kerman University of Medical Sciences' Ethics Committee with the ethics code of IR.KMU.REC.1396.179.

\section{Results}

A total of 404 cases of oral potentially malignant lesions and SCC were evaluated. The mean patient age was $46.82 \pm 15.22$ years; $57.6 \%$ of lesions were in men and $42.4 \%$ in women. Buccal mucosa was the most common lesion site with 294 cases $(72.05 \%)$, followed by tongue with 75 cases (18.38\%) (Figure 1).

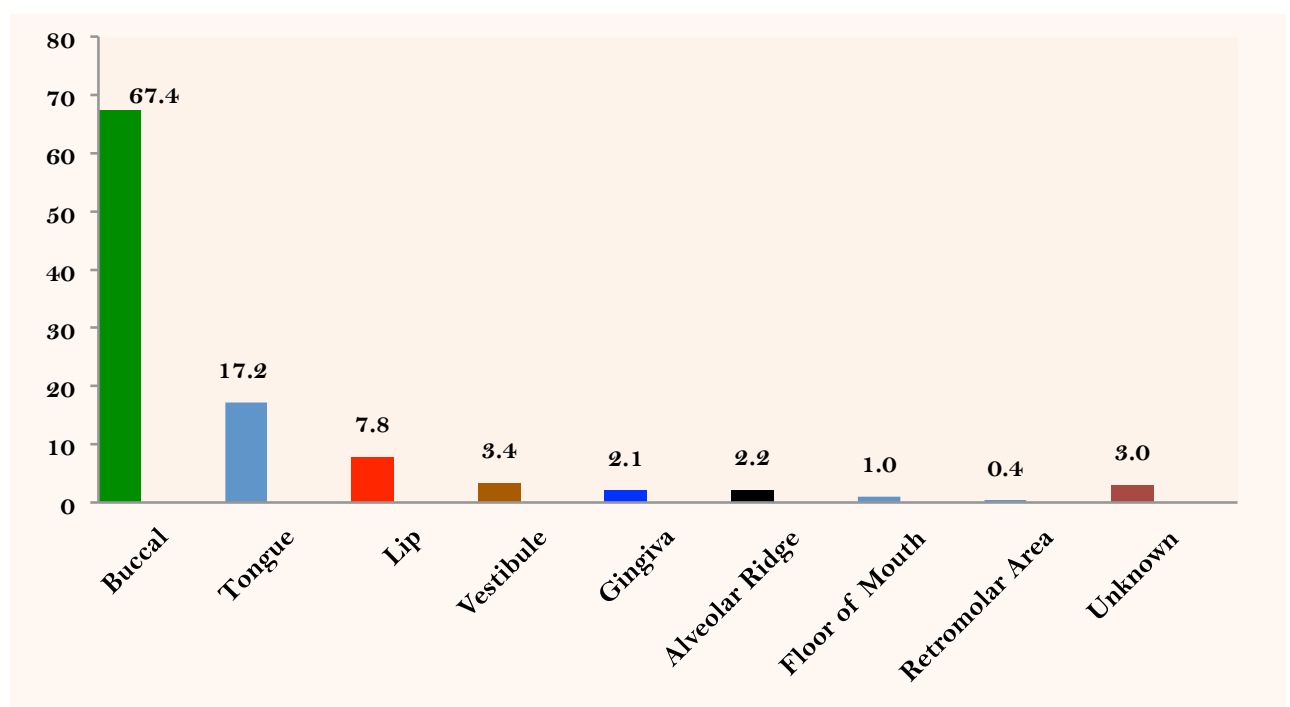

Figure 1. Lesions distribution according to the area.

According to histopathologic diagnoses, out of 408 cases, lichen planus was observed in 282 cases (69.8\%), followed by SCC in 67 cases (17.32\%). Figure 2 presents the distribution frequency of lesions based on the histopathologic diagnosis.

The mean age of women was significantly higher than males $(p=0.61)$. Moreover, the mean age of OSCC patients $(59.44 \pm 17.55$ years) was higher than those with OPMD. The lowest mean age $(45.14 \pm 13.71)$ was observed in lichen planus patients. Correlation between the mean age of gender with different lesions is shown in Table 1. There was no significant difference between men and women's mean age in lichen planus, OSCC, and dysplasia. The clinical and histopathological diagnoses were consistent in $69.33 \%$ of the cases, including lichen planus in $76.4 \%$, OSCC in $98.1 \%$, and leukoplakia in $40 \%$ of the cases. Clinical and 
histopathological diagnoses were inconsistent in all erythroplakia cases. The Cohen's kappa statistic for consistency of the histopathologic and clinical diagnoses was 0.617 .

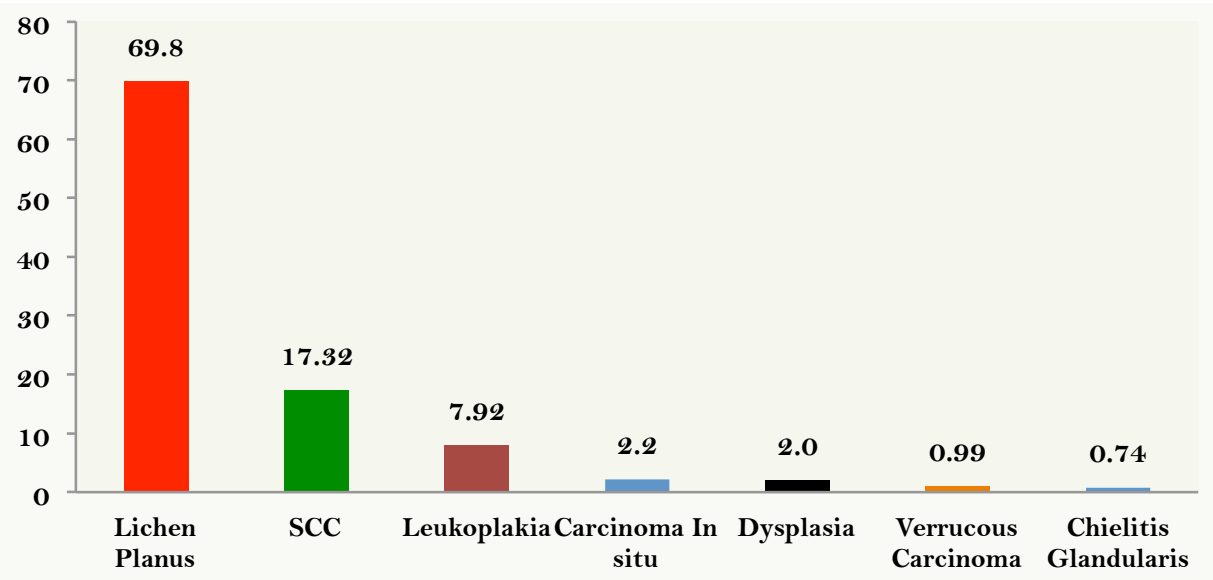

Figure 2. Distribution of lesions based on histopathologic diagnosis.

Table 1. Association between lesions and genders' age.

\begin{tabular}{|c|c|c|c|c|c|}
\hline Lesion & Gender & $\mathbf{N}$ & Mean & SD & p-value \\
\hline \multirow[t]{2}{*}{ Lichen Planus } & Male & 92 & 44.17 & 13.99 & 0.386 \\
\hline & Female & 190 & 45.64 & 13.57 & \\
\hline \multirow[t]{2}{*}{ Oral Squamous Cell Carcinoma } & Male & 29 & 59.96 & 19.79 & 0.316 \\
\hline & Female & 38 & 61.34 & 15.62 & \\
\hline \multirow[t]{2}{*}{ Leukoplakia } & Male & 24 & 45.87 & 10.72 & 0.002 \\
\hline & Female & 8 & 62.14 & 12.52 & \\
\hline \multirow[t]{2}{*}{ Dysplasia } & Male & 5 & 48.60 & 4.39 & 0.309 \\
\hline & Female & 2 & 65.00 & 12.72 & \\
\hline \multirow[t]{2}{*}{ Carcinoma in situ } & Male & 5 & 42.20 & 5.21 & 0.037 \\
\hline & Female & 4 & 65.75 & 8.30 & \\
\hline
\end{tabular}

\section{Discussion}

The possibility of OPMD developing into carcinoma has been reported in 5-18\% of cases [17,18]. In the present study, the mean patient age was $46.82 \pm 15.22$ years. Similar studies showed the mean age of OPMD patients was 56.09 [11] and 55 years [19], slightly higher than the current study.

This research revealed that $57.6 \%$ of lesions were in men and $42.4 \%$ in women. In a study by Casparis et al. [20], 38.2\% of lesions were observed in men and $61.6 \%$ in women. This finding is not consistent with the current research results, which may be accounted for by varying types of lesion in these studies.

Buccal mucosa was the most common lesion site in the present research. Lower lip and oral mucosa [10] and oral mucosa and alveolar ridge [11] lower lip and palate [21] was the most frequent location. In the present study, lichen planus was the most frequent lesion occurring most commonly in buccal mucosa; therefore, this can justify buccal mucosa as the most common lesion site in this research.

Lichen planus, found in $69.8 \%$ of the cases, was the most frequent potentially malignant lesion in the present study. This finding was inconsistent with the other studies [11] actinic cheilitis as the most frequent lesion and leukoplakia as the most common lesion [22-25]. In a systematic review, 85 out of 7806 cases of oral lichen planus and 4 out of 125 cases of lichenoid lesions progressed to SCC. The malignancy progress rate was $0 \%-3.5 \%$ in different studies [25]. In this study, lichen planus was more common in women than in men. The mean patient age was $45.14 \pm 13.71$ years. This finding is consistent with other studies [19,26,27]. 
Buccal mucosa was the most common site for lichen planus. According to literature, oral mucosa is the most common site for oral lichen planus. The epithelium's thickness and the degree of oral keratinization are believed to be the reasons [28].

In the current study, $17.32 \%$ of lesions were SCC with a mean patient age of $59.44 \pm 17.55$ years and a higher prevalence in women than in men. The mean age of women was higher, albeit with no significant difference. This finding differs from similar studies in which the lesion was more common in men [19,28]. This difference can be attributed to the higher frequency of women visiting dental centers.

In this study, leukoplakia accounted for $7.92 \%$ of lesions. Leukoplakia has been reported as the most common OPMD in many studies [22,29,30]. The global prevalence of leukoplakia is 2.6\% [31]. This difference can be attributed to the study population and method. Leukoplakia was more common in men than in women in the present study. This finding is consistent with the study of Vázquez-Álvarez et al. [32]. The mean age of patients with leukoplakia was $49.54 \pm 12.93$. Women were significantly older than men. Most cases of oral leukoplakia were shown to occur in the third to fifth decades of life in developing countries, whereas the majority were over 40 years of age in developed countries [33]. Leukoplakia is called OPMD. This term does not indicate the severity of the disease and the potential for developing into a malignancy [5]. The progression risk to malignancy was reported between 0.13 and $34 \%$ [34]

Seven cases of dysplasia were observed in the current study. It was shown that dysplasia of the oral cavity might show the lichenoid histology, which can cover its potentially malignant appearance [35].

In this study, carcinoma in situ accounted for $2.06 \%$ of the lesions. According to some specialists, carcinoma in situ is a precancerous lesion, while others believe that the lesion is a real malignancy discovered before invasion [34].

The clinical diagnosis was consistent with histopathologic diagnosis in $69.03 \%$ of the cases. In Abidullah et al. study [36], clinicopathologic relationship of 100 white lesions was $78 \%$ and Maia et al. [11] showed that the potentially malignant oral lesions were $78.1 \%$. This difference may arise from the type of study.

The highest percentage of correlation between clinical and histopathological diagnosis was observed in OSCC. This may be because the samples were from the School of Dentistry and oral specialists are completely familiar with the clinical manifestations of OSCC.

Oral leukoplakia reached $40 \%$ of coincidence between clinical and histopathological diagnoses. This may be that since leukoplakia is a clinical term and does not indicate a specific histopathological presentation, the degree of clinical presentation with histopathology has been low. In the current study, clinical and histopathological diagnoses were inconsistent in all erythroplakia cases. It has been shown that $90 \%$ of the erythroplakia lesions are histopathologically severe dysplasia, carcinoma in situ, or superficial invasive squamous cell carcinoma [37].

It was shown that increased experience of a surgeon and greater association with pathologists could reduce the difference between clinical diagnosis and histopathology [38]. The difference in the clinical and histopathologic diagnoses might be partly caused by the fact that the clinical information did not accompany the biopsy specimen and the pathologist was not aware of the clinical presentation and exact location of the lesion. In addition to clinical features, the microscopic examination and radiographic view of the lesions are necessary for a definitive diagnosis [13].

\section{Conclusion}


Lichen planus was the most common lesion and buccal mucosa was the most common site. The lesions were more prevalent in males. In $69.03 \%$ of cases, clinical diagnosis was consistent with the histopathologic diagnosis. The highest percentage of correlation between clinical and histopathological diagnosis was observed in oral squamous cell carcinoma. Further studies are recommended on the risk factors associated with oral potentially malignant disorders.

\section{Authors' Contributions}

\begin{tabular}{|c|c|c|}
\hline MT & (D) https://orcid.org/0000-0002-3116-2382 & Conceptualization and Writing - Review and Editing. \\
\hline MKA & (i) https://orcid.org/0000-0003-4485-5476 & $\begin{array}{l}\text { Conceptualization, Formal Analysis, Data Curation, Writing - Original Draft, Writing - Review } \\
\text { and Editing and Supervision. }\end{array}$ \\
\hline HMA & -- & Writing - Review and Editing. \\
\hline IM & (D) https://orcid.org/0000-0001-6351-3119 & $\begin{array}{l}\text { Conceptualization, Methodology, Investigation, Writing - Original Draft and Writing - Review } \\
\text { and Editing. }\end{array}$ \\
\hline
\end{tabular}

\section{Financial Support}

None.

\section{Conflict of Interest}

The authors declare no conflicts of interest.

\section{Data Availability}

The data used to support the findings of this study can be made available upon request to the corresponding author.

\section{References}

[1] Dineshkumar T, Ashwini BK, Rameshkumar A, Rajashree P, Ramya R, Rajkumar K. Salivary and serum interleukin-6 levels in oral premalignant disorders and squamous cell carcinoma: diagnostic value and clinicopathologic correlations. Asia Pac J cancer Prev 2016; 17(11):4899-4906. https://doi.org/10.22034/APJCP.2016.17.11.4899

[2] Pałasz P, Adamski L, Górska-Chrząstek M, Starzyńska A, Studniarek M. Contemporary diagnostic imaging of oral squamous cell carcinoma - a review of literature. Pol J Radiol 2017; 82:193-202. https://doi.org/10.12659/PJR.900892

[3] Carreras-Torras C, Gay-Escoda C. Techniques for early diagnosis of oral squamous cell carcinoma: Systematic review. Med Oral Patol Oral Cir Bucal 2015; 20(3):e305-e315. https://doi.org/10.4317/medoral.20347

[4] Remmerbach TW, Meyer-Ebrecht D, Aach T, Würflinger T, Bell AA, Schneider TE, et al. Toward a multimodal cell analysis of brush biopsies for the early detection of oral cancer. Cancer 2009; 117(3):228-35. https://doi.org/10.1002/cncy.20028

[5] Narayan TV, Shilpashree S. Meta-analysis on clinicopathologic risk factors of leukoplakias undergoing malignant transformation. J Oral Maxillofac Pathol 2016; 20(3):354-61. https://doi.org/10.4103/0973-029X.190900

[6] Rethman MP, Carpenter W, Cohen EE, Epstein J, Evans CA, Flaitz CM, et al. Evidence-based clinical recommendations regarding screening for oral squamous cell carcinomas. J Am Dent Assoc 2010; 141(5):509-20. https://doi.org/10.14219/jada.archive.2010.0223

[7] Sloan P. Squamous cell carcinoma and precursor lesions: clinical presentation. Periodontol 2000 2011; 57(1):10-8. https://doi.org/10.1111/j.1600-0757.2011.00391.x

[8] Warnakulasuriya S, Johnson NW, van der Waal I. Nomenclature and classification of potentially malignant disorders of the oral mucosa. J Oral Pathol Med 2007; 36(10):575-80. https://doi.org/10.1111/j.1600-0714.2007.00582.x

[9] Jeddy N, Ravi S, Radhika T. Screening of oral potentially malignant disorders: Need of the hour. J Oral Maxillofac Pathol 2017; 21(3):437-8. https://doi.org/10.4103/jomfp.JOMFP_217_17

[10] Bokor-Bratíc M, Vucković N, Mirković S. Correlation between clinical and histopathologic diagnosis of potentially malignant oral lesions. Arch Oncol 2004; 12(3):145-7. https://doi.org/10.2298/AOO0403145B

[11] Maia HC, Pinto NA, Pereira J dos S, de Medeiros AM, da Silveira ÉJ, Miguel MC. Potentially malignant oral lesions: clinicopathological correlations. Einstein 2016; 14(1):35-40. https://doi.org/10.1590/S1679-45082016AO3578

[12] Abbey LM, Kaugars GE, Gunsolley JC, Burns JC, Page DG, Svirsky JA, et al. Intraexaminer and interexaminer reliability in the diagnosis of oral epithelial dysplasia. Oral Surg Oral Med Oral Pathol Oral Radiol Endod 1995; 80(2):188-91. https://doi.org/10.1016/s1079-2104(05)80201-x

[13] Eversole LR. Evidence-based practice of oral pathology and oral medicine. J Calif Dent Assoc 2006; 34(3):448-54. 
[14] Torabi M, Shahravan A, Bahabin A, Mohammadzadeh I, Afshar MK. Internet addiction among Iranian students of medical sciences. Pesqui Bras Odontopediatria Clín Integr 2020; 20:e5387. https://doi.org/10.1590/pboci.2020.056

[15] Afshar MK, Torabi M, Bahremand M, Afshar MK, Najmi F, Mohammadzadeh I. Oral health literacy and related factors among pregnant women referring to Health Government Institute in Kerman, Iran. Pesqui Bras Odontopediatria Clín Integr 2020; 20:e5337. https://doi.org/10.1590/pboci.2020.011

[16] Zihayat B, Khodadadi A, Torabi M, Mehdipour M, Basiri M, Asadi-Shekarri M. Wound healing activity of sheep's bladder extracellular matrix in diabetic rats. Biomed Eng: Appl Basis Commun 2018; 30(2):1850015. https://doi.org/10.4015/S1016237218500151

[17] Moro A, Di Nardo F, Boniello R, Marianetti TM, Cervelli D, Gaspardini G, et al. Autofluorescence and early detection of mucosal lesions in patients at risk for oral cancer. J Craniofac Surg 2010; 21(6):1899-903. https://doi.org/10.1097/SCS.0bo13e3181f4afb4

[18] Rana M, Zapf A, Kuehle M, Gellrich NC, Eckardt AM. Clinical evaluation of an autofluorescence diagnostic device for oral cancer detection: a prospective randomized diagnostic study. Eur J Cancer Prev 2012; 21(5):460-6. https://doi.org/10.1097/CEJ.obo13e32834fdb6d

[19] Mehrotra R, Pandya SH, Chaudhary AK, Kumar M, Singh M. Prevalence of Oral Pre-malignant and Malignant Lesions at a Tertiary Level Hospital in Allahabad, India. Asian Pacific J Cancer Prev 2008; 9(2):263-266.

[20] Casparis S, Borm JM, Tektas S, Kamarachev J, Locher MC, Damerau G, et al. Oral lichen planus (OLP), oral lichenoid lesions (OLL), oral dysplasia, and oral cancer: retrospective analysis of clinicopathological data from 20022011. Oral Maxillofac Surg 2015; 19(2):149-56. https://doi.org/10.1007/s10006-014-0469-y.

[21] Silveira ÉJ, Lopes MF, Silva LM, Ribeiro BF, Lima KC, Queiroz LM. Potentially malignant oral lesions: clinical and morphological analysis of 205 cases. J Bras Patol Med Lab 2009; 45(3):233-8. https://doi.org/10.1590/S167624442009000300008.

[22] Feller L, Lemmer J. Oral Leukoplakia as It Relates to HPV Infection: A Review. Int J Dent 2012; $2012: 540561$. https://doi.org/10.1155/2012/540561.

[23] Haas Jr. OL, Rosa FM, Burzlaff JB, Rados PV, Sant'Ana Filho M. Definition of risk group for oral leukoplakia: retrospective study between the years 1999 and 2009. Rev Fac Odont 2011; 16(3):261-6.

[24] Martins RB, Giovani EM, Villalba H. Lesions considered malignant that affect the mouth. Rev Inst Ciênc Saúde. 2008; 26(4):467-76.

[25] Fitzpatrick SG, Hirsch SA, Gordon SC. The malignant transformation of oral lichen planus and oral lichenoid lesions: a systematic review. J Am Dent Assoc 2014; 145(1):45-56. https://doi.org/10.14219/jada.2013.10.

[26] Soares MS, Honório AP, Arnaud RR, Oliveira Filho FD. Oral conditions in patients with oral lichen planus. Pesq Bras Odontoped Clin Integr 2012; 11(4):507-10. https://doi.org/10.4034/pboci.v1 1i4.1024.

[27] Sousa FA, Rosa LE. Oral lichen planus cases epidemic profile from Oral Pathology Discipline from FOSJC - UNESP. Cienc Odont Bras 2005; 8(4):96-100.

[28] Idris A, Vani N, Saleh S, Tubaigy F, Alharbi F, Sharwani A, et al. Relative frequency of oral malignancies and oral precancer in the biopsy service of Jazan province, 2009-2014. Asian Pac J Cancer Prev 2016; 17(2):519-25. https://doi.org/10.7314/apjcp.2016.17.2.519

[29] Pereira J dos S, Carvalho M de V, Henriques AC, de Queiroz Camara TH, Miguel MC, Freitas R de A. Epidemiology and correlation of the clinicopathlogical features in oral epitelial displasia: Analysis of 173 cases. Ann Diagn Pathol 2011; 15(2):98-102. https://doi.org/10.1016/j.anndiagpath.2010.08.008

[30] Sciubba JJ. Oral cancer: The importance of early diagnosis and treatment. Am J Clin Dermatol 2001; 2(4):239-51. https://doi.org/10.2165/00128071-200102040-00005

[31] Hanken H, Kraatz J, Smeets R, Heiland M, Assaf AT, Blessmann M, et al. The detection of oral pre- malignant lesions with an autofluorescence based imaging system $\left(\right.$ VELscope $\left.^{\mathrm{TM}}\right)$ - a single blinded clinical evaluation. Head Face Med 2013; 9:23. https://doi.org/10.1186/1746-160X-9-23

[32] Vázquez-Álvarez R, Fernández-González F, Gándara-Vila P, Reboiras-López D, García-García A, Gándara-Rey JM. Correlation between clinical and pathologic diagnosis in oral leukoplakia in 54 patients. Med Oral Patol Oral Cir Bucal 2010; 15(6):e832-8.

[33] Villa A, Woo SB. Leukoplakia - A diagnostic and management algorithm. J Oral Maxillofac Surg 2017; 75(4):723-34. https://doi.org/10.1016/j.joms.2016.10.012

[34] Natekar M, Raghuveer HP, Rayapati DK, Shobha ES, Prashanth NT, Rangan V, et al. A comparative evaluation: Oral leukoplakia surgical management using diode laser, CO2 laser, and cryosurgery. J Clin Exp Dent 2017; 9(6):e779-84. https://doi.org/10.4317/jced.53602.

[35] Müller S. Oral lichenoid lesions: distinguishing the benign from the deadly. Mod Pathol 2017; 30(s1):S54-S67. https://doi.org/10.1038/modpathol.2016.121

[36] Abidullah M, Raghunath V, Karpe T, Akifuddin S, Imran S, Dhurjati VN, et al. Clinicopathologic correlation of white, non scrapable oral mucosal surface lesions: a study of 100 cases. J Clin Diagn Res 2016; 10(2):ZC38-41. https://doi.org/10.7860/JCDR/2016/16950.7226

[37] Nevil BW, Damm DD, Allen CM, Chi AC. Dermatologic Diseases. In.: Nevil BW, Damm DD, Allen CM, Chi AC Oral and Maxillofacial Pathology. $4^{\text {th }}$. ed. Philadelphia: W. B. Saunders Co.; 2016. Chapter 16; pp. 673-677. 
[38] Powsner SM, Costa J, Homer RJ. Clinicians are from Mars and pathologists are from Venus. Arch Pathol Lab Med 2000; 124(7):1040-6. 